\title{
Evidence for Compartmentalized Axonal Mitochondrial Biogenesis: Mitochondrial DNA Replication Increases in Distal Axons As an Early Response to Parkinson's Disease-Relevant Stress
}

\author{
Victor S. Van Laar, ${ }^{1,2}$ Beth Arnold, ${ }^{1,2}$ Evan H. Howlett, ${ }^{1,2}$ Michael J. Calderon, ${ }^{3,4} \mathbb{C}_{\text {Claudette M. St. Croix, }}^{3,4}$ \\ (D). Timothy Greenamyre, ${ }^{1,2}$ Laurie H. Sanders, ${ }^{1,2,5}$ and (DSarah B. Berman ${ }^{1,2}$ \\ ${ }^{1}$ Department of Neurology, ${ }^{2}$ The Pittsburgh Institute for Neurodegenerative Diseases, University of Pittsburgh, Pittsburgh, Pennsylvania 15213, \\ ${ }^{3}$ Department of Cell Biology, ${ }^{4}$ The Center for Biologic Imaging, University of Pittsburgh, Pittsburgh, Pennsylvania 15261, and ${ }^{5}$ Department of Neurology, \\ Duke University Medical Center, Durham, North Carolina 27710
}

Dysregulation of mitochondrial biogenesis is implicated in the pathogenesis of neurodegenerative diseases such as Parkinson's disease (PD). However, it is not clear how mitochondrial biogenesis is regulated in neurons, with their unique compartmentalized anatomy and energetic demands. This is particularly relevant in PD because selectively vulnerable neurons feature long, highly arborized axons where degeneration initiates. We previously found that exposure of neurons to chronic, sublethal doses of rotenone, a complex I inhibitor linked to $\mathrm{PD}$, causes early increases in mitochondrial density specifically in distal axons, suggesting possible upregulation of mitochondrial biogenesis within axons. Here, we directly evaluated for evidence of mitochondrial biogenesis in distal axons and examined whether PD-relevant stress causes compartmentalized alterations. Using BrdU labeling and imaging to quantify replicating mitochondrial DNA (mtDNA) in primary rat neurons (pooled from both sexes), we provide evidence of mtDNA replication in axons along with cell bodies and proximal dendrites. We found that exposure to chronic, sublethal rotenone increases mtDNA replication first in neurites and later extending to cell bodies, complementing our mitochondrial density data. Further, isolating axons from cell bodies and dendrites, we discovered that rotenone exposure upregulates mtDNA replication in distal axons. Utilizing superresolution stimulated emission depletion (STED) imaging, we identified mtDNA replication at sites of mitochondrial-endoplasmic reticulum contacts in axons. Our evidence suggests that mitochondrial biogenesis occurs not only in cell bodies, but also in distal axons, and is altered under PD-relevant stress conditions in an anatomically compartmentalized manner. We hypothesize that this contributes to vulnerability in neurodegenerative diseases.

Key words: axonal; biogenesis; mitochondrial; neurodegeneration; Parkinson's disease; rotenone

Significance Statement

Mitochondrial biogenesis is crucial for maintaining mitochondrial and cellular health and has been linked to neurodegenerative disease pathogenesis. However, regulation of this process is poorly understood in CNS neurons, which rely on mitochondrial function for survival. Our findings offer fundamental insight into these regulatory mechanisms by demonstrating that replication of mitochondrial DNA, an essential precursor for biogenesis, can occur in distal regions of CNS neuron axons independent of the soma. Further, this process is upregulated specifically in axons as an early response to neurodegeneration-relevant stress. This is the first demonstration of the compartmentalized regulation of CNS neuronal mitochondrial biogenesis in response to stress and may prove a useful target in development of therapeutic strategies for neurodegenerative disease.

\section{Introduction}

Neurons are dependent on mitochondria for survival and function and mitochondrial homeostasis is maintained via regulated fission, fusion, active transport, degradation, and biogenesis, collectively termed mitochondrial dynamics (Detmer and Chan,

research; V.S.V., B.A., E.H.H., M.J.C., C.M.S.C., L.H.S., and S.B.B. performed research; V.S.V., B.A., E.H.H., M.J.C., C.M.S.C., J.T.G., L.H.S., and S.B.B. analyzed data.

This work was supported by the National Institutes of Health (Grant R01NS077954 to S.B.B.), the University of Pittsburgh Physicians Academic Foundation (Research Grant to S.B.B), the DSF Charitable Foundation, and the 
2007). Together, these dynamic processes regulate mitochondrial DNA (mtDNA) stability, mitochondrial turnover, cell death mechanisms, and proper distribution of mitochondria to synapses (Detmer and Chan, 2007). Disruption of mitochondrial dynamics is detrimental to neuronal survival and has been increasingly implicated in the pathogenesis of neurodegenerative diseases such as Parkinson's disease (PD) (Van Laar and Berman, 2009, 2013; McCoy and Cookson, 2012; Bose and Beal, 2016).

In $\mathrm{PD}$, mitochondrial biogenesis may be the important link between dysregulation of mitochondrial homeostasis and neurodegeneration. Mitochondrial biogenesis is a complex process involving mtDNA replication, coordinated gene expression, protein synthesis, membrane formation, and mitochondrial division (Nisoli et al., 2004). The degenerative process in PD is thought to begin in distal axons of vulnerable neurons (Braak et al., 2004), which feature long, poorly myelinated, and highly branched axons with high ATP requirements (Braak et al., 2004; Surmeier et al., 2017). Mitochondrial biogenesis is likely to be critical in these distal, highly energy-requiring regions and growing evidence implicates dysregulation of mitochondrial biogenesis in PD. For example, it was discovered that neurodegeneration caused by mutations in the familial PD genes PINK1 and parkin is due in part to suppression of activity of the "master mitochondrial biogenesis regulator," transcription coactivator PPAR gammacoactivator $1 \alpha(\mathrm{PGC} 1 \alpha)$ (Stevens et al., 2015; Lee et al., 2017). In addition, overexpression of the familial PD gene $\alpha$-synuclein causes neurodegeneration in zebrafish that is prevented by upregulating PGC1 $\alpha$ expression (O'Donnell et al., 2014), further implicating a critical role for biogenesis in PD.

Neurons, especially those in the CNS, have unique anatomical and functional characteristics with extended axons and arborization. However, it is not known whether regulation of mitochondrial biogenesis takes place throughout this extended arborization. In our previous work, we studied early changes in mitochondrial dynamics in CNS neurons in a chronic PD-relevant toxicant model (Arnold et al., 2011). Unexpectedly, we discovered that mitochondrial density in distal axons increased early after chronic nonlethal rotenone exposure without a concomitant increase inside cell bodies. However, the axonal mitochondrial density changes could not be explained by alterations in mitochondrial axonal transport nor did we find evidence of decreased mitochondrial degradation (Arnold et al., 2011). Therefore, the mitochondrial increase exclusively in axons suggests an unconventional hypothesis: that mitochondrial biogenesis can occur in distinct, anatomically compartmentalized distal axons. It also suggests that compartmentalized biogenesis may increase as an early response to chronic neurotoxic PD-relevant stress, specifically in distal axonal regions where neurodegeneration starts.

It is generally presumed that mitochondrial biogenesis takes place exclusively in cell bodies near nuclear machinery for protein translation with new mitochondria transported down axons (Davis and Clayton, 1996; Li et al., 2017). However, for postmitotic neurons with long, branched axons, this seems an inadequate means of replacing dysfunctional mitochondria at synaptic

William N. and Bernice E. Bumpus Foundation (Innovation Award to L.H.S.). We thank Simon Watkins and Mads Larsen of the University of Pittsburgh Center for Biologic Imaging for their imaging expertise and assistance during these studies.

The authors declare no competing financial interests.

Correspondence should be addressed to Dr. Sarah B. Berman, Department of Neurology, Pittsburgh Institute for Neurodegenerative Diseases, University of Pittsburgh, Biomedical Science Tower 3, 7037, 3501 Fifth Avenue, Pittsburgh,PA 15213. E-mail: bermans@upmc.edu.

DOl:10.1523/JNEUROSCI.0541-18.2018

Copyright $\odot 2018$ the authors $\quad 0270-6474 / 18 / 387506-11 \$ 15.00 / 0$ terminals. It is known that mRNA of mitochondrially targeted proteins can be transported down axons and that translation of these mRNAs are essential for maintaining axonal mitochondrial function (Gioio et al., 2001; Hillefors et al., 2007; Kar et al., 2014). Evidence of mtDNA replication in proximal neurites of peripheral neurons has been reported (Amiri and Hollenbeck, 2008; Lentz et al., 2010), but evidence for distal axonal biogenesis in CNS neurons has never been described nor have distinct, compartmentalized alterations under CNS disease-relevant conditions.

Therefore, we investigated these fundamental questions, testing the hypothesis that mitochondrial biogenesis in CNS neurons is not limited to cell bodies, but also occurs in distal axons. We then evaluated for evidence of anatomic compartmentalization of mitochondrial biogenesis, investigating whether biogenesis increases in distal axons in response to chronic neurotoxic PDrelevant stress distinct from and before changes in cell body mitochondrial biogenesis. Our findings provide evidence for mitochondrial biogenesis in distal axons with early upregulation in response to $\mathrm{PD}$-relevant stress.

\section{Materials and Methods \\ Primary neuron culture and treatment}

Primary cortical neurons were cultured as described previously (Arnold et al., 2011). Briefly, neurons were derived from embryonic day 18 (E18) Sprague Dawley rats (pooled from both male and female embryos) and plated in serum-containing Neurobasal medium at a density of $3 \times 10^{5}$ cells $/ \mathrm{ml}$ on glass coverslips coated with poly-D-lysine and mouse laminin. Media were replaced with serum-free Neurobasal media and half of the media was changed every 3-4 d. Treatments with $1 \mathrm{~nm}$ rotenone or DMSO vehicle were initiated at $7 \mathrm{~d}$ in vitro (DIV7) and continued with regular feedings for 1-2 weeks. For microfluidic device culture, standard two-chamber microfluidic neuron devices with a $450 \mu \mathrm{m}$ - or $900 \mu \mathrm{m}$ width microgroove barrier (Xona Microfluidics) were placed on coverslips coated with poly-D-lysine. Neurons were plated in the cell body chamber at 50,000 cells per device. After plating, no media changes occurred until the initial treatment with $1 \mathrm{~nm}$ rotenone or DMSO vehicle control at DIV7, with a half media change in both the axonal and cell body chambers. Treatments continued with half media changes every 3-4 d.

\section{Transfection of cortical neurons}

Cells were transfected on DIV6 using Lipofectamine 2000 as described previously (Arnold et al., 2011). Briefly, cell culture media was saved and exchanged for transfection incubation media (MEM, pH 7.4, 2\% Glutamax, 20 mм HEPES, 33 mm glucose, 1 mm Na-pyruvate; Thermo Fisher Scientific). Cells were incubated with transfection media at $37^{\circ} \mathrm{C}$ in a non- $\mathrm{CO}_{2}$ incubator for $1.5 \mathrm{~h}$ and then media was replaced. Neurons were transfected where noted with plasmids expressing mitochondrially targeted DsRed2 (mtDsRed2; Clontech), mitochondrially targeted photoactivatable GFP (PA-mtGFP) (Karbowski et al., 2004), and/or green fluorescent protein-tagged endoplasmic reticulum (ER) protein Sec61 $\beta$ (GFP-Sec61 $\beta$; Addgene plasmid 15108; deposited by T. Rapoport) (Voeltz et al., 2006). We routinely obtain $100 \%$ cotransfection with multiple plasmids (Arnold et al., 2011).

\section{BrdU and EdU detection and immunocytochemistry}

At the specified time points and/or following chronic rotenone or DMSO vehicle control treatments, cells were treated with either BrdU (10 $\mu \mathrm{M}$; Sigma-Aldrich) or EdU (10 $\mu \mathrm{M}$; ThermoFisher Scientific) for the indicated length of time. For negative controls, DMSO vehicle control cells either were not treated with thymidine analogs or were pretreated for $6 \mathrm{~h}$ with $100 \mu \mathrm{M} 22^{\prime}, 3^{\prime}$-dideoxycytidine (ddC) followed by cotreatment of $\mathrm{ddC}$ and thymidine analog. Immediately following BrdU or EdU exposure, cells were rinsed with PBS and then fixed using 4\% PFA at room temperature (RT) for $20 \mathrm{~min}$. For BrdU detection, cells were permeabilized in $0.5 \%$ Triton X-100 in PBS on ice for $5 \mathrm{~min}$, treated with $2 \mathrm{~N} \mathrm{HCl}$ 
for 30 min at RT to denature the DNA, and rinsed with PBS. Cells then underwent sequential fluorescent immunocytochemical staining. Cells were first stained for BrdU (mouse anti-BrdU, 1:1000; BD PharMingen catalog \#555627). Briefly, cells were blocked in normal donkey serum for $30 \mathrm{~min}$, incubated with BrdU primary overnight at $4^{\circ} \mathrm{C}$, followed by $1 \mathrm{~h}$ incubation with secondary (donkey anti-mouse Alexa Fluor 488, 1:500; Thermo Fisher Scientific; donkey anti-mouse Alexa Fluor 555, 1:500, Thermo Fisher Scientific). Cells were then rinsed in PBS and incubated with either MAP2 (rabbit anti-MAP2, 1:1000; Millipore catalog \#ab5622) or mitochondrial single-stranded DNA binding protein (rabbit antimtSSBP, 1:2000; Origene catalog \#TA314569) primaries again overnight at $4^{\circ} \mathrm{C}$, followed by $1 \mathrm{~h}$ incubation with secondary (donkey anti-rabbit Cy3, 1:500, Jackson ImmunoResearch; donkey anti-rabbit 647, 1:500, Thermo Fisher Scientific). Coverslips were rinsed in PBS followed by $\mathrm{ddH}_{2} \mathrm{O}$ and mounted onto slides using Gelvatol mounting medium. For experiments using neurons transfected with PA-mtGFP, BrdU immunochemical detection and mounting was performed as described above. PA-mtGFP in fixed neurons was photoactivated via brief exposure to 405 $\mathrm{nm}$ laser as described previously (Berman et al., 2009), which increases GFP fluorescence of this protein 100-fold when excited at $488 \mathrm{~nm}$ (Karbowski et al., 2004). The photoactivatable fluorescence property of PAmtGFP was unaffected by acid treatment as evidenced by robust green fluorescence in mitochondria after activation (see Fig. $1 A-D$ ). For EdU detection, fixed cells were stained using the EdU Click-iT Alexa Fluor 647 kit from Thermo Fisher Scientific per the manufacturer's instructions and mounted on slides using ProLong Gold mounting medium (Thermo Fisher Scientific).

For immunocytochemical detection of equilibrative nucleoside transporter 1 (ENT-1), neurons were cultured on microfluidic devices and transfected on DIV7 to express mtDsRed2. Cell were fixed on DIV14 and immunocytochemistry was performed using rabbit anti-ENT-1 (1:100; Alomone catalog \#ANT-051) primary overnight at $4^{\circ} \mathrm{C}$, followed by $1 \mathrm{~h}$ incubation with secondary (donkey anti-rabbit Cy3, 1:500, Jackson ImmunoResearch). Cells were rinsed in PBS and mounted using ProLong Gold mounting medium (Thermo Fisher Scientific).

For immunocytochemical detection of cytochrome oxidase subunit IV (COXIV), neurons cultured on microfluidic devices were treated with DMSO vehicle control or $1 \mathrm{~nm}$ rotenone for 1 week as described above. After fixation, immunocytochemistry was performed using mouse antiCOXIV (1:1000; Abcam catalog \#ab14744) primary antibody overnight at $4^{\circ} \mathrm{C}$, followed by $1 \mathrm{~h}$ incubation with secondary antibody (donkey anti-mouse Alexa Fluor 555, 1:500; Thermo Fisher Scientific). To detect actin, cells were then incubated with $165 \mathrm{~nm}$ Alexa Fluor 488 Phalloidin (Thermo Fisher Scientific) for $20 \mathrm{~min}$ at RT, followed by washing in PBS and mounting using ProLong Gold mounting medium (Thermo Fisher Scientific).

\section{BrdU imaging and analyses}

All images for assessing BrdU incorporation were acquired using an Olympus IX81 inverted microscope with a FV1000 laser scanning confocal system with a $60 \times 1.42$ numerical aperture (NA) oil-immersion objective. To assess BrdU in neurons cultured on coverslips, image stacks were taken at $1024 \times 1024$ pixel resolution $(0.207 \mu \mathrm{m} /$ pixel $)$ with 0.50 $\mu \mathrm{m} z$-steps. To assess BrdU in neurons grown in microfluidic devices, image stacks of random fields of distal axons on the axon chamber side were taken at $1024 \times 1024$ pixel resolution with $0.25 \mu \mathrm{m} z$-steps and random fields of cell bodies on the cell body chamber side of the device were taken at $1024 \times 1024$ pixel resolution with $0.50 \mu \mathrm{m} z$-steps. After acquisition, images were analyzed using the Fiji distribution of ImageJ (Schindelin et al., 2012; Schneider et al., 2012). BrdU detection in image fields from experimental groups was thresholded to fields taken from negative control cells not exposed to BrdU using Fiji Color Threshold (using the brightness function). For BrdU puncta analysis, cell bodies were first identified and outlined as regions of interest (ROIs). Fiji particle analysis with the size limit set to $0-5$ pixels was then used to count the number of BrdU puncta either within ROIs (e.g., in cell bodies; represented as "puncta per cell") or outside the ROIs (e.g., in neuritic processes, represented as "puncta in processes per field").

\section{COXIV imaging and analyses}

For experiments assessing COXIV protein levels via quantitative immunofluorescence, all images were acquired using an Olympus IX81 inverted microscope with a FV1000 laser scanning confocal system using a $60 \times 1.42$ NA oil-immersion objective at $2 \times$ magnification and $1024 \times$ 1024 pixel resolution $(0.103 \mu \mathrm{m} / \mathrm{pixel})$. Vehicle control- or rotenonetreated neuronal cultures grown on microfluidic devices were stained and mounted as described above. Cells were imaged using identical laser and detector settings across devices within an experiment for both control and rotenone conditions. For axon imaging, random fields of axons on the axon chamber side of the device were imaged with $0.25 \mu \mathrm{m}$ $z$-steps. Similarly, random fields of cell bodies on the cell body chamber side of the device were imaged with $0.50 \mu \mathrm{m} z$-steps. For COXIV intensity quantification in axons, image analysis was done using Nikon Elements. 3D spot detection was used to characterize individual mitochondria and 3D thresholding was used to measure actin volume. Identical threshold settings for COXIV fluorescence intensity were used for control- and rotenone-treated conditions within each experiment. Only COXIV-positive puncta colocalizing with actin were used for analysis. Data are reported as COXIV intensity normalized to actin volume. For COXIV intensity quantification in the soma, individual neuronal cell bodies were outlined as ROIs and the total intensity and area of each cell body was assessed using Olympus FV10-ASW Version 4.06 software. Data are reported as COXIV intensity normalized to ROI area.

\section{Western blot analyses}

Neurons were cultured on poly-D-lysine/laminin-coated six-well dishes and treated as described above. Cells were collected by scraping into ice-cold PBS, pelleted, and immediately lysed in a small volume of urea/ CHAPS lysis buffer ( $9 \mathrm{~m}$ urea, $2 \%$ CHAPS, in $30 \mathrm{~mm}$ Tris, with $1 \times$ protease inhibitor mixture; Sigma-Aldrich). Protein concentrations were determined by the Bradford method (Bradford, 1976; Hammond and Kruger, 1988) and samples stored at $-80^{\circ} \mathrm{C}$ until use. Samples were diluted in a reducing sample buffer ( $\mathrm{Li}$-Cor) and boiled before use. Protein samples were then subjected to SDS-PAGE using Bio-Rad precast TGX gels and transferred to PVDF using a Bio-Rad SemiDry Transfer apparatus. Western blots of the gels were then probed using rabbit antiPGC1 $\alpha$ (1:2000; Novus catalog \#NBP1-04676), mouse anti-actin (1:40,000, EMD Millipore catalog \#MAB1501), mouse anti-COXIV (1:25,000; Abcam catalog \#ab14744), and rabbit anti-ATP synthase subunit 9 (anti-ATP5G1, 1:2000; Abcam catalog \#ab180149). Li-Cor Odyssey-compatible IR680- and IR800-conjugated goat secondary antibodies (Li-Cor) were used for detection and blots were imaged and analyzed using a Li-Cor Odyssey Infrared Imaging System equipped with Odyssey Application Software version 3.0.30.

\section{Stimulated emission depletion (STED) superresolution imaging of mitochondrial-ER interaction}

Primary cortical neurons were cotransfected with mtDsRed2 and GFPSec61 $\beta$ at DIV6. At DIV14, cells were treated with EdU (10 $\mu \mathrm{M})$ for $3 \mathrm{~h}$, then fixed and fluorescently stained for EdU using the Click-iT Alexa Fluor 647 kit (Thermo Fisher Scientific), and immunofluorescently stained for GFP using chicken anti-GFP (1:500; Abcam catalog \#ab13970) and goat anti-chicken Alexa 488 (Thermo Fisher Scientific). STED superresolution microscopy was used to examine EdU staining relative to mitochondria and ER. STED microscopy was taken with a Leica TCS SP8 STED $3 \times$ system using Leica LAS X software. Image stacks were taken with $0.019 \mu \mathrm{m}$ pixels and $0.100 \mu \mathrm{m} z$-steps using a $100 \times 1.4$ NA STED objective. A pulsed white light laser was used to excite the fluorophores and emissions were collected using a filterless acoustooptical beam splitter system. DsRed2 was excited at $558 \mathrm{~nm}$ and emissions collected from 563 to $648 \mathrm{~nm}$. Alexa Fluor 488 was excited at 496 $\mathrm{nm}$ and emissions collected from 500 to $553 \mathrm{~nm}$. Alexa Fluor 647 was excited at 653 and emissions collected from 658 to $767 \mathrm{~nm}$. A pulsed 775 $\mathrm{nm}$ STED laser was used to achieve superresolution. All emissions were temporally gated from 1.3 to $6 \mathrm{~ns}$ after the excitation pulse. 

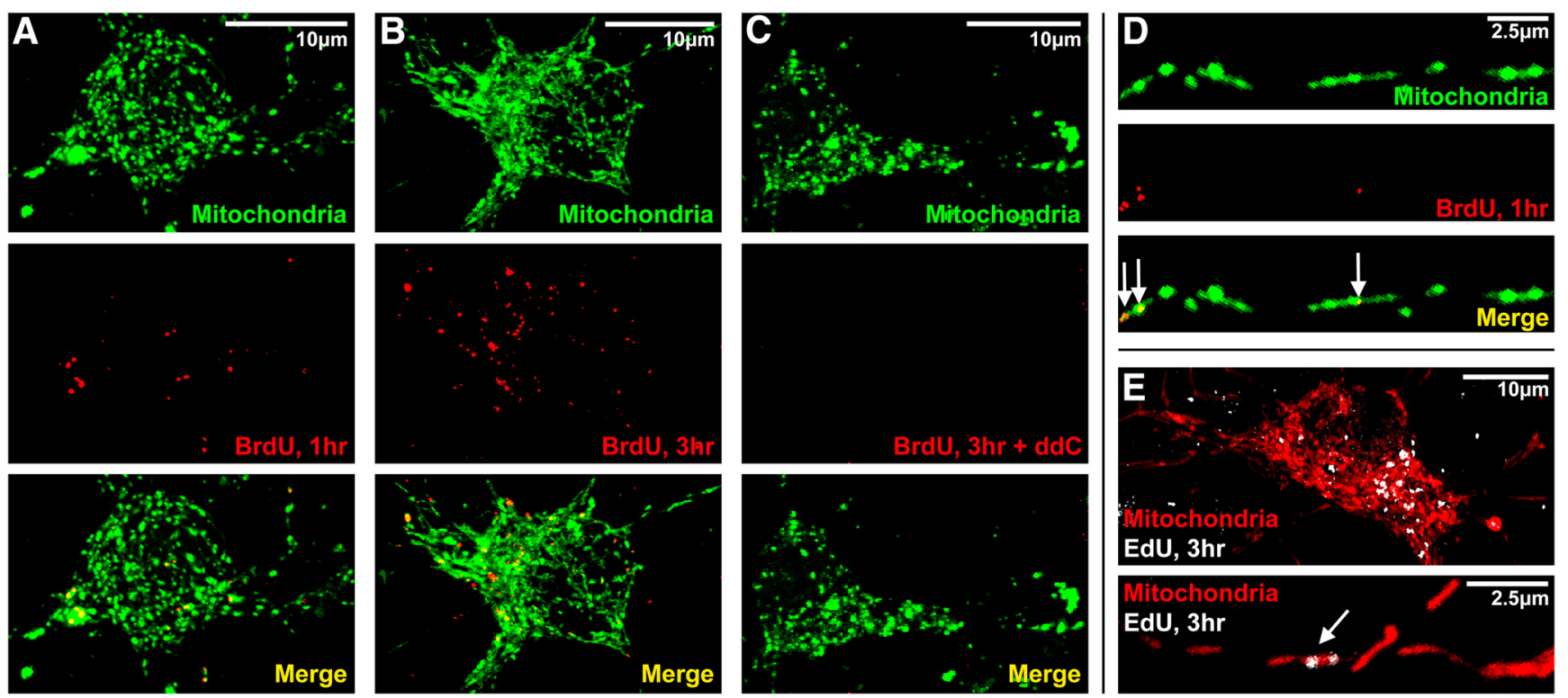

Figure 1. Incorporation of BrdU and EdU into neuronal mitochondria in cell bodies and axons within $1-3 \mathrm{~h}$ of exposure. $A-C$, Primary neurons (DIV14) expressing mitochondrially targeted photoactivatible GFP (Mitochondria) were treated with $10 \mu \mathrm{m}$ BrdU for $1 \mathrm{~h}(\boldsymbol{A})$ or $3 \mathrm{~h}(\boldsymbol{B})$. Control cells were incubated with $100 \mu \mathrm{m} \mathrm{ddC}$, an inhibitor of mitochondrial DNA polymerase gamma, for $6 \mathrm{~h}$ before and then during $3 \mathrm{~h}$ of BrdU exposure (C). Cells were immunofluorescently stained for BrdU and confocal imaging revealed BrdU puncta associated with mitochondria in cell bodies $(\boldsymbol{A}, \boldsymbol{B})$, but minimal, if any, incorporation when ddC was present ( $\boldsymbol{C}$, confirming specificity for mtDNA replication. $\boldsymbol{D}$, BrdU puncta were also found in mitochondria of distal axons after $1 \mathrm{~h}$ of BrdU exposure. E, Primary neurons (DIV14) expressing mitochondrially targeted DsRed2 (Mitochondria) were treated with EdU for $3 \mathrm{~h}$ and then stained using the EdU Click-iT system. EdU-positive puncta were again observed in mitochondria of the cell body and axons ( $\boldsymbol{E}$, arrow).

\section{Experimental design and statistical analysis}

For data shown in Figures 2 and 3, primary cortical neurons from three to six separate, independent neuronal preparations (as indicated) were cultured on glass coverslips in individual wells of a 24-well dish or in individual microfluidic devices as described above. Neurons were cultured until DIV7 and then individual wells/devices were divided into three groups: controls exposed only to DMSO vehicle and not to BrdU (Control No BrdU), DMSO vehicle followed by BrdU treatment (Control + BrdU), or 1 nM rotenone followed by BrdU treatment (Rotenone + $\mathrm{BrdU})$. After treatments, cells were subjected to immunochemical staining and imaging as described above. Each individual field from the Control + BrdU and Rotenone + BrdU cells was thresholded to experiment-paired Control No BrdU fields and quantified for BrdU puncta in cell bodies and outside cell bodies per field as described above. Data for the Control + BrdU and Rotenone + BrdU groups were compared and statistically analyzed by unpaired, two-tailed $t$ test using GraphPad Prism analysis software (version 7.0c).

For data shown in Figure 4, $A-J$, primary cortical neurons from four separate, independent neuronal preparations were cultured in six-well culture dishes as described above. Neurons were cultured to DIV7 and then wells were divided into two groups: DMSO vehicle control and $1 \mathrm{~nm}$ rotenone. Each condition was done in duplicate or triplicate on separate dishes, resulting in $n=11-13$ for each condition across four independent neuronal preparations. After 1 or 2 weeks of treatments, cells were collected and subjected to Western blot and immunochemical detection analysis as described above. Data for the DMSO vehicle and 1 nM rotenone groups were compared and statistically analyzed by unpaired, twotailed $t$ test using GraphPad Prism analysis software (version 7.0c). For COXIV intensity analysis (see Fig. $4 K-N$ ) primary cortical neurons from three separate, independent neuronal preparations (as indicated) were cultured in individual microfluidic devices as described above. Neurons were cultured to DIV7 and then individual wells/devices were divided into two groups: controls exposed to DMSO vehicle or to $1 \mathrm{~nm}$ rotenone. After 1 week of treatments, cells were subjected to immunochemical staining and imaging as described above. Each individual field from the axon chamber images and each individual cell from the cell chamber images from the Control and Rotenone groups were quantified as described above and data were compared and statistically analyzed by unpaired, two-tailed $t$ test using GraphPad Prism analysis software (version 7.0c).

\section{Results}

\section{Detection of BrdU and EdU incorporation in primary} neurons as a measure of mtDNA replication

To assess specific anatomic localization of mitochondrial biogenesis within the neuron, we first optimized methodology to localize and quantify markers of biogenesis via incorporation of the thymidine analog BrdU into mtDNA in cultured neurons as a measure of mtDNA replication (Amiri and Hollenbeck, 2008; Lentz et al., 2010). To establish mitochondrial BrdU detection in CNS neurons, we exposed primary cortical neurons at DIV14 to $10 \mu \mathrm{M} \mathrm{BrdU}$ for various time points (15 min to $72 \mathrm{~h}$ ) and then fixed the cells. We then developed an immunocytochemical methodology that provided clear detection of BrdU-positive puncta in both cell bodies and neurites as described in the Materials and Methods. We were able to detect mitochondrial BrdU incorporation within neurons as early as $15 \mathrm{~min}$ (data not shown), but consistent results were obtained at $1 \mathrm{~h}$ of incubation, similar to previous studies (Davis and Clayton, 1996). To verify mitochondrial localization, neurons were transfected at DIV6 to express mitochondrially targeted PA-mtGFP, a mitochondrial marker that we found to be resistant to the acid treatment required in the BrdU immunochemical detection process. At DIV14, neurons were then treated with BrdU. At $1 \mathrm{~h}, \mathrm{BrdU}$ incorporation was detected specifically in mitochondria both in soma and in distal axons (Fig. $1 A, D$ ). As expected, BrdU puncta increased with prolonged $(3 \mathrm{~h}) \mathrm{BrdU}$ incubation (Fig. $1 B$ ). Further, we did not observe BrdU in the nuclei of neurons because they are postmitotic cells. To further verify that BrdU puncta represented incorporation into mtDNA, we used $\mathrm{ddC}$, an inhibitor of mitochondrial polymerase gamma (Zimmermann et al., 1980; Starnes and Cheng, 1987), as a negative control. Cotreatment of $10 \mu \mathrm{M}$ BrdU with $100 \mu \mathrm{M}$ ddC prevented BrdU incorporation even after $3 \mathrm{~h}$ of BrdU incubation (Fig. 1C).

To further verify our findings with BrdU, we evaluated mtDNA replication using another thymidine analog, EdU, which 

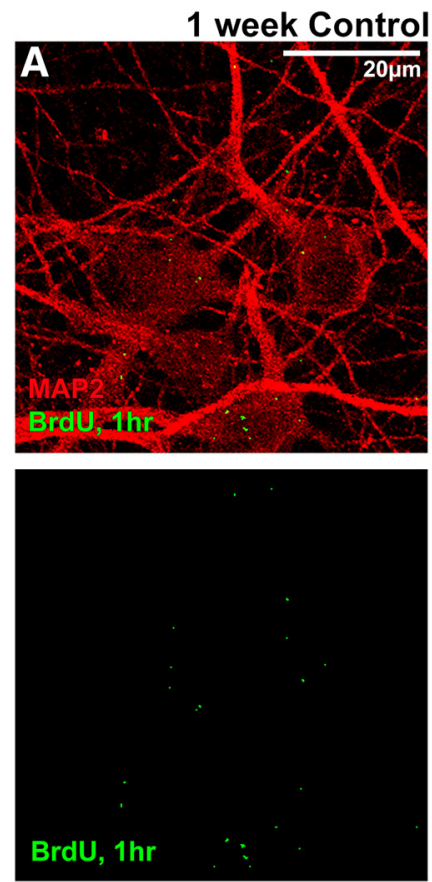

C BrdU Puncta per Cell Body

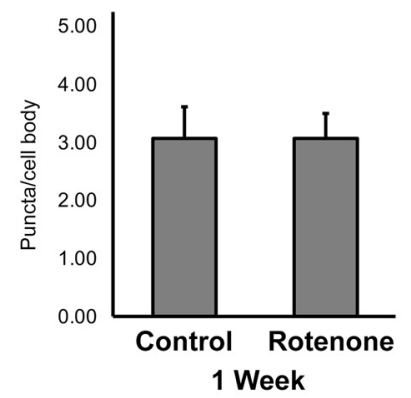

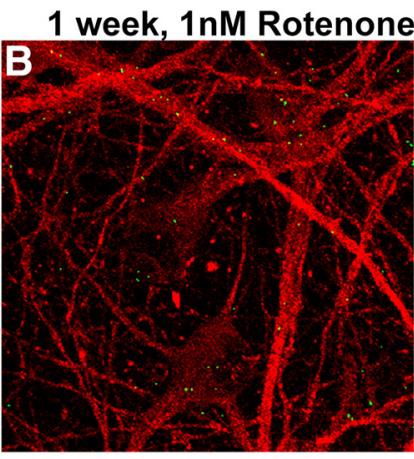

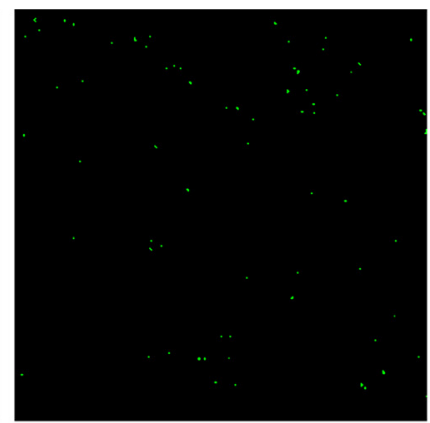

D BrdU Puncta in Neurites

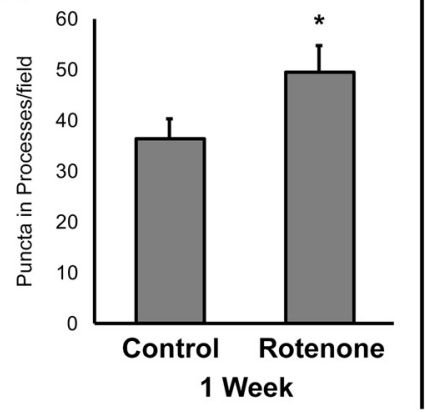

2 week Control
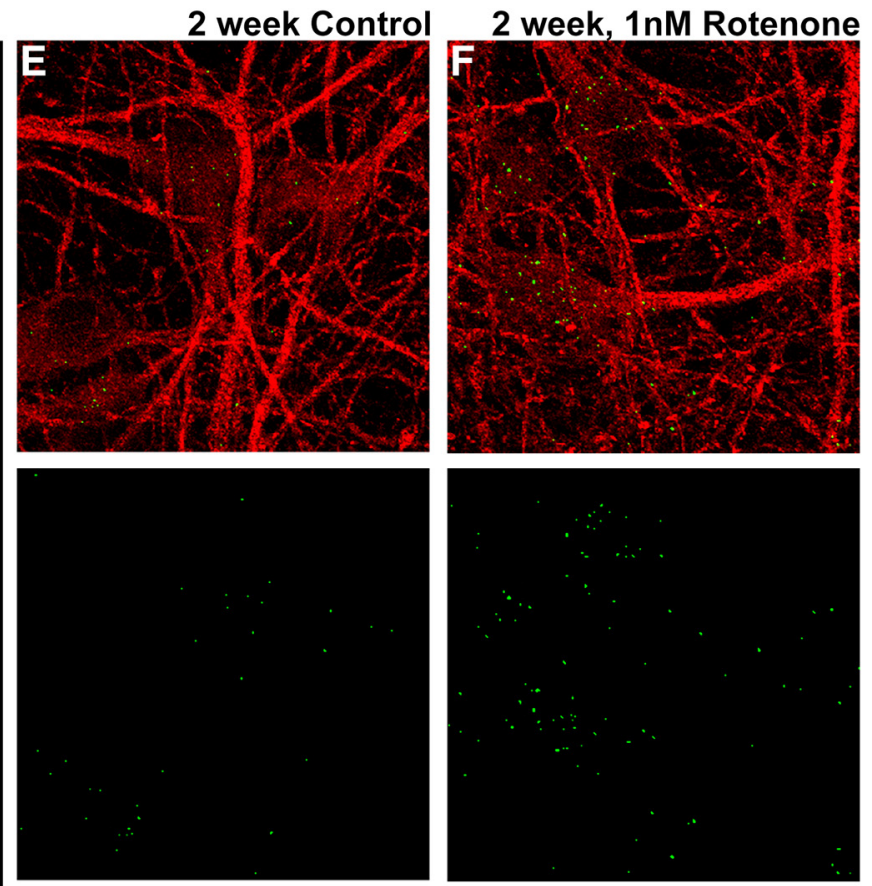

G BrdU Puncta per Cell Body $\quad H$

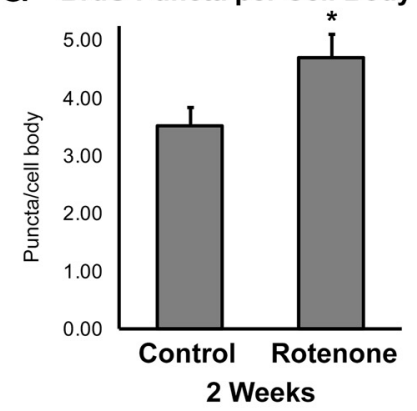

H BrdU Puncta in Neurites

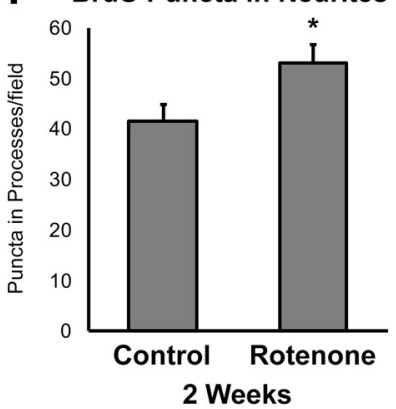

Figure 2. Quantifying localized mtDNA replication in soma and neurites of primary neurons in response to chronic exposure to rotenone. $\boldsymbol{A}, \boldsymbol{B}$, Representative confocal $z$-stack images of neurons exposed to $10 \mu \mathrm{m}$ BrdU for $1 \mathrm{~h}$ following exposure to 1 week of DMSO vehicle control $(\boldsymbol{A})$ or $1 \mathrm{~nm}$ rotenone $(\boldsymbol{B})$. $\boldsymbol{C}$, Quantitative analysis of BrdU puncta revealed no difference in number of puncta per cell body between control and rotenone at 1 week $\left(t_{(78)}=0.012 ; p=0.99\right.$; two-tailed unpaired $t$ test; puncta/cell body \pm SEM). $D$, In neurites, we observed a significantly increased number of BrdU puncta of rotenone-exposed neurons compared with vehicle control at 1 week (difference in means $=+13.2 ; t_{(78)}=2.02 ;{ }^{*} p=0.047$; two-tailed unpaired $t$ test; puncta in processes/field \pm SEM; $n=38$ control and $n=42$ rotenone image fields representing three independent neuronal preps). $\boldsymbol{E}$, $\boldsymbol{F}$, Representative confocal $z$-stack images of neurons exposed to $10 \mu \mathrm{m}$ BrdU for $1 \mathrm{~h}$ following exposure to 2 weeks of DMSO vehicle control $(\boldsymbol{E})$ or 1 nm rotenone $(\boldsymbol{F}) . \boldsymbol{G}, \boldsymbol{H}$, Quantitative analysis of BrdU puncta revealed significant rotenone-associated increases in both cell bodies ( $\boldsymbol{G}$; difference in means $=+1.2 ; t_{(81)}=2.34 ;{ }^{*} p=0.022 ;$ two-tailed unpaired $t$ test; puncta/cell body \pm SEM) and neurites $\left(\boldsymbol{H} ;\right.$ difference in means $=+11.3 ; t_{(81)}=2.32 ;{ }^{*} p=0.023 ;$ two-tailed unpaired $t$ test; puncta in processes/field \pm SEM) compared with vehicle control at 2 weeks ( $n=40$ control and $n=43$ rotenone image fields representing three independent neuron preps \pm SEM).

can be detected via a "click chemistry" reaction (Haines et al., 2010; Lentz et al., 2010), eliminating the acid denaturation required for immunochemical BrdU detection. Neurons expressing $\mathrm{mtDsRed}$ were exposed to $10 \mu \mathrm{M}$ EdU for $3 \mathrm{~h}$. Similar to BrdU, we observed mitochondria-specific EdU puncta in both the soma and distal neurites of primary neurons (Fig. 1E).

Chronic, sublethal rotenone exposure increases mtDNA replication rates first in neurites and later in cell bodies As noted above, we previously observed that mitochondrial density increased only in distal axons after a 1 week exposure to chronic sublethal doses of rotenone (Arnold et al., 2011). After 2 weeks of chronic rotenone, we then observed increased mitochondrial density in both distal axons and cell bodies (Arnold et al., 2011). These data suggested the possibility of increased axonspecific mitochondrial biogenesis as an early response to chronic stress. To test this hypothesis, we investigated whether chronic, low-dose rotenone exposure affected mtDNA replication in a similar neuroanatomic and temporal pattern. Beginning at DIV7, primary neurons were exposed to $1 \mathrm{nM}$ rotenone or DMSO vehicle control for 1 or 2 weeks, a rotenone concentration that we showed previously to result in minimal cell death (Arnold et al., 2011). Following rotenone treatment, neurons were pulsed for $1 \mathrm{~h}$ with $10 \mu \mathrm{M}$ BrdU, immunostained for BrdU and MAP2 (which in these cultures, identify neuronal cell bodies, dendrites, and, weakly, axons), and evaluated by confocal analyses (Fig. 2). To evaluate anatomical localization of BrdU puncta, image fields were processed to count puncta present specifically within cell bodies and outside cell bodies, as described in the Materials and Methods.

Following 1 week of exposure to rotenone, we observed no change in mtDNA replication in the cell bodies (Fig. 2C). However, we observed a significant increase in the numbers of BrdU puncta detected in neurites of primary neurons $(50 \pm 5$ neurite puncta per field) compared with vehicle-exposed control neurons $(36 \pm 4$ neuritic puncta per field, $p=0.047$ ), a 1.4 -fold increase (Fig. 2D). After 2 weeks of rotenone exposure, we then 
A

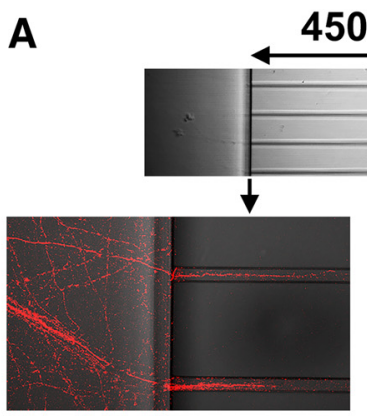

C
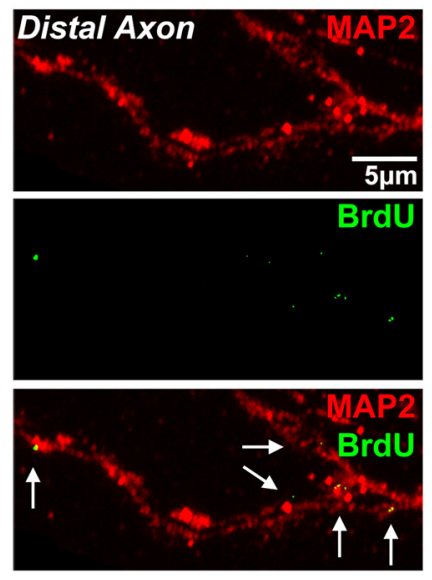

$450 \mu \mathrm{m}$
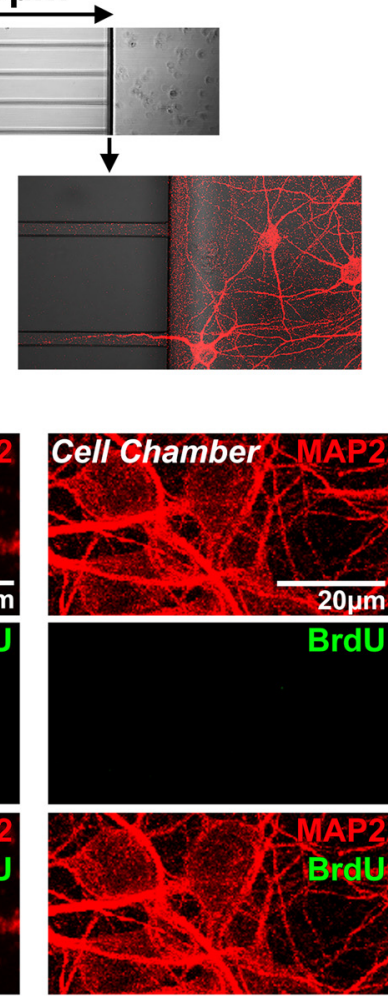

B

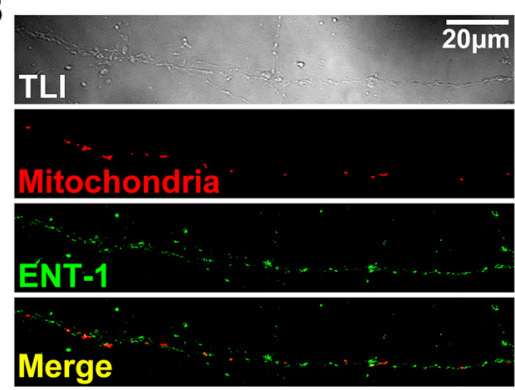

D

\section{Distal Axonal mtDNA Replication in Microfluidic Devices}

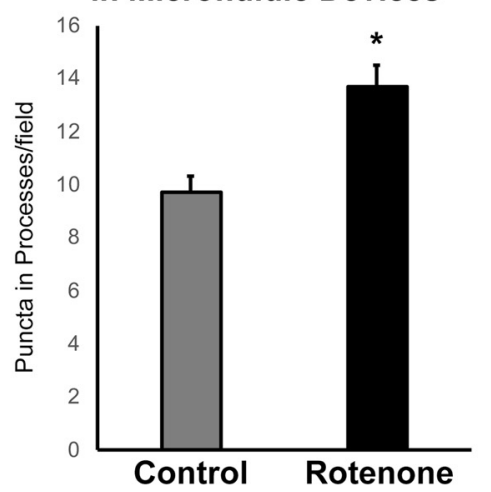

Figure 3. Distal axonal mtDNA replication is increased in response to chronic rotenone. $A$, Primary neurons were seeded into one side of microfluidic devices (Xona Microfluidics) to environmentally separate cell bodies and dendrites from axons for BrdU incorporation assessments. B. Neurons were transfected to express mitochondrially targeted mtDsRed2 (Mitochondria) and at DIV14 were immunofluorescently stained to detect ENT-1 to ensure that axons were capable of importing BrdU on their own. TLI, Transmitted light image. C, Following 1 week of DMSO vehicle (shown) or $1 \mathrm{~nm}$ rotenone, only the axons were exposed to $10 \mu \mathrm{m}$ BrdU for $3 \mathrm{~h}$. Confocal imaging of immunofluorescence for BrdU incorporation show that axon-localized BrdU puncta can be found distally from the microfluidic grooves (arrows), with no BrdU incorporation on the cell chamber side of the device. This suggests that mtDNA replication does occur locally in distal axons. $D$, Quantification of BrdU puncta demonstrated that mtDNA replication in distal axons was significantly increased following 1 week of chronic 1 nm rotenone exposure compared with DMSO vehicle control $(n=123$ image fields per condition representing six independent neuron preps; difference in means $=+3.9 ; t_{(244)}=4 ;{ }^{*} p=0.0001$; two-tailed unpaired $t$ test; puncta in processes/field \pm SEM).

observed a significant increase in mtDNA replication rates in the soma ( $4.7 \pm 0.4 \mathrm{BrdU}$ puncta per cell body) compared with vehicle-exposed control neurons $(3.5 \pm 0.3 \mathrm{BrdU}$ puncta per cell body, $p=0.022$ ) (Fig. $2 G$ ). Also, neuritic mtDNA replication remained significantly elevated at 2 weeks of rotenone exposure (53 \pm 4 neurite puncta per field) compared with vehicle-exposed control neurons (42 \pm 3 neuritic puncta per field, $p=0.023$ ) (Fig. $2 H$ ). These data complement our previously observed early increase in axonal mitochondrial density after chronic rotenone exposure (Arnold et al., 2011). Although incorporation of thymidine analogs occurs after DNA damage and repair, this is considered unlikely to contribute significantly to signal from these short BrdU incubations (Davis and Clayton, 1996). Further, we have shown previously that 10 -fold higher doses of rotenone did not elicit any mtDNA damage in primary rat cortical neurons (Sanders et al., 2014).

mtDNA replication occurs specifically in distal axons and rates are increased by low-level, chronic rotenone exposure The above results demonstrate that mitochondria with evidence of active mtDNA replication can be found in axons and dendrites and also that rates of mtDNA replication increase in a compartmentalized manner following chronic rotenone exposure. However, these studies cannot unequivocally confirm that the increased mtDNA replication is occurring specifically in distal axons, where we previously observed early rotenone-associated increases in mitochondrial density (Arnold et al., 2011). Given the distribution of axons, dendrites, and neuronal cell bodies across our cultures, it was not possible to identify distal axons conclusively. In addition, whereas we used the shortest BrdU incubation period possible to differentiate mtDNA replication in neurites from replication in cell bodies, we could not completely rule out an influence of axonal anterograde transport of newly made mitochondria originating from the cell body. Therefore, to answer definitively whether mtDNA replication, and therefore biogenesis, can occur specifically in distal axons, we used microfluidic devices in which we could isolate axons from cell bodies and dendrites and could limit BrdU exposure to axonal mitochondria.

Neurons were cultured in microfluidic cell culturing devices with microchannels, environmentally separating cell bodies from their distal axon projections by 450 or $900 \mu \mathrm{m}$, allowing us to specifically evaluate distal axons (Fig. 3A) (Taylor et al., 2005). We first confirmed that axons contain the transporter that imports nucleosides, including BrdU, ENT-1 (Sivakumar et al., 2004). Immunocytochemistry revealed that primary cortical neuron distal axons do exhibit ENT-1 (Fig. 3B). After verifying this, cell and axon chambers were treated for 1 week with $1 \mathrm{nM}$ rotenone or DMSO vehicle control as described above. At DIV14 ( 1 week of rotenone exposure), only the axon chamber of the microfluidic device was exposed to $10 \mu \mathrm{M}$ BrdU for $3 \mathrm{~h}$. We then evaluated whether mtDNA replication could occur directly in distal axons. We indeed found $\mathrm{mtDNA}$ replication in the most distal axons $>500-1000 \mu \mathrm{m}$ from the channels $(>1000-2000 \mu \mathrm{m}$ from their 
cell bodies; Fig. 3C). Importantly, there was no BrdU incorporation observed on the cell body chamber side of the device after $3 \mathrm{~h}$ of incubation with BrdU in the axon chamber (Fig. $3 C$ ). This eliminated the possibility that BrdU was diffusing from the axons to the cell bodies on the other side of the channel, becoming incorporated into replicating mtDNA in the cell body, and then being transported in those mitochondria back to distal axons. In addition, cotreatment of the DNA polymerase inhibitor ddC exclusively in the axon chamber resulted in a significant decrease in detectable BrdU puncta ( $12 \pm 0.8$ puncta/field after $3 \mathrm{~h} \mathrm{BrdU}$ vs $7 \pm 0.6$ puncta/field after BrdU $+\mathrm{ddC} ; n=48 \mathrm{BrdU}+\mathrm{ddC}$ and $n=73 \mathrm{BrdU}$ control fields representing four independent neuron preps; difference in means $=-4.6 \pm 1.1 ; t_{(119)}=4.2 ; p=$ 0.000055; two-tailed unpaired $t$ test). Therefore, BrdU puncta present in the axons represent incorporation into $\mathrm{mtDNA}$, originating there, rather than soma-based mitochondrial replication followed by transport.

We next examined the effect of rotenone specifically on distal axonal mtDNA replication. Both axon and cell body chambers were treated with $1 \mathrm{~nm}$ rotenone for 1 week. We then exposed the axon chamber only to $10 \mu \mathrm{M}$ BrdU for $3 \mathrm{~h}$. We found that a 1week treatment with rotenone significantly increased the rate of mtDNA replication $(13.7 \pm 0.8$ puncta per field) in distal axons compared with vehicle-exposed control $(9.8 \pm 0.6$ puncta per field, $p=0.0001$; Fig. $3 D$ ). This represents a 1.6-fold increase in mtDNA replication, in agreement with our previous results. This provided further proof that chronic exposure to low-dose, nonlethal concentrations of rotenone triggers direct, distal axonal mtDNA replication.

\section{Changes in abundance of PGC1 $\alpha$, COXIV, and ATP5G1 in neurons follow different time courses after chronic rotenone exposure}

To further assess mitochondrial biogenesis, we examined changes in levels of the mitochondrial biogenesis regulator and transcriptional coactivator PGC1 $\alpha$ in cultured neurons (Fig. 4). Protein lysates from neurons after 1 week of chronic rotenone exposure did not reveal any changes in PGC1 $\alpha$ levels, but PGC1 $\alpha$ abundance significantly increased after 2 weeks of rotenone exposure compared with vehicle control ( 2 weeks of rotenone PGC1 $\alpha$ levels at $112 \%$ of control; $p=0.0013$; Fig. $4 C, H)$. This suggests the possibility of distinct mechanisms for early axonal changes in biogenesis compared with later cell body increases. To further evaluate this possibility, we examined levels of electron transport chain COXIV. COXIV mRNA has been reported to be transported down distal axons and locally synthesized (Gioio et al., 2001; Aschrafi et al., 2016). We hypothesized that, if local biogenesis were occurring in distal axons, then we might see temporal asynchrony between PGC1 $\alpha$ levels and upregulation of axonally translated mitochondrial protein levels. Specifically, we might expect rotenone exposure to lead to earlier increase in COXIV abundance (due to distal biogenesis) without a concomitant increase in PGC1 $\alpha$ (acting at the nucleus later to upregulate transcription). Supporting this, we found that, unlike PGC1 $\alpha$, COXIV levels were significantly increased following only 1 week of rotenone exposure compared with vehicle control (1 week rotenone COXIV levels at $151 \%$ of control, $p=0.020$ ) and remained significantly elevated after 2 weeks ( 2 weeks rotenone COXIV levels at $133 \%$ of control, $p=0.044$; Fig. $4 D, I$ ). To add further support, we examined changes in levels of a second mitochondrial protein, ATP5G1, a component of ETC complex V. ATP5G1 mRNA has also been demonstrated to be transported down axons and locally translated there (Natera-Naranjo et al.,
2012). Like COXIV levels, we found that ATP5G1 levels were also increased after 1 week of chronic rotenone exposure ( 1 week of rotenone ATP5G1 levels at $143 \%$ of control, $p=0.028)$ and remained elevated after 2 weeks of exposure relative to vehicletreated control (2 weeks of rotenone ATP5G1 levels at 123\% of control, $p=0.014$; Fig. $4 E, J)$.

To further test the hypothesis that the early upregulated mitochondrial protein levels were indeed due to distal axonal mitochondrial biogenesis, we used the microfluidic chambers to separate immunochemical analysis of axons from cell bodies and dendrites and evaluated anatomically localized COXIV levels after 1 week of DMSO vehicle control or $1 \mathrm{~nm}$ rotenone exposure via immunocytochemistry (Fig. $4 K, M$ ). In axons, we found that COXIV protein levels were significantly increased following 1 week of $1 \mathrm{~nm}$ rotenone compared with vehicle control ( 1 week of rotenone axonal COXIV levels at $132 \%$ of control, $p=0.0005$; Fig. $4 L$ ). However, COXIV levels in the soma were not different between vehicle control and rotenone at 1 week (Fig. $4 N$ ). These data suggest that the increase in whole-cell COXIV abundance that we detected after 1 week of rotenone is largely due to the increase in COXIV protein levels specifically in the axons.

\section{Evidence of mtDNA replication at mitochondrial-ER interaction sites within axons}

Mitochondrial replication and distribution to daughter mitochondria were recently reported to be initiated at mitochondrial-ER contact sites in replicating mammalian cells and yeast (Murley et al., 2013; Lewis et al., 2016). However, although the ER has been demonstrated to extend throughout axonal networks in the CNS (Luarte et al., 2018), mtDNA replication at mitochondrial-ER contact sites in axons had never been demonstrated. We therefore examined the interaction of mitochondria and ER at sites of active mtDNA replication within axons. Primary cortical neurons were transfected to express mtDsRed 2 and GFP-tagged ER protein Sec61beta (GFP-Sec61beta). After 1 week of expression, neurons were exposed to $10 \mu \mathrm{M}$ EdU for $3 \mathrm{~h}$, fixed, and stained for both GFP and EdU. Using STED microscopy, we examined both soma and axons. We observed mitochondrial-ER interactions within the soma and neurites (Fig. 5). In neurites, the mitochondria appeared to be nearly enveloped by ER (Fig. $5 B, C)$. Some mitochondria also displayed evidence of mtDNA replication via EdU incorporation. We observed mitochondria which exhibited EdU puncta at their tips (Fig. 5B), which, based on previous studies (Lewis et al., 2016), would suggest recently divided mitochondria, where division occurred at the site of mtDNA replication. We also observed mitochondria with EdU incorporation occurring at midpoints within their length as opposed to the tips. At these points, ER showed intimate interaction with the mitochondria, wrapping around and overlapping the mtDNA replication site (Fig. $5 C$ ). This is, to our knowledge, the first observation of mtDNA replication site interactions with ER in axons, providing further evidence of active biogenesis away from the cell body.

As further evidence that biogenesis likely takes place in axons, we performed immunocytochemistry for mtSSBP, which binds specifically to single-stranded mtDNA during replication (Curth et al., 1994; Tiranti et al., 1995). After 3 h of BrdU exposure, we observed mtSSBP puncta colocalized to sites of BrdU incorporation within distal axonal mitochondria (Fig. 5D).

\section{Discussion}

In these studies, we provide evidence supporting the hypotheses that mitochondrial biogenesis occurs in distal CNS axons in ad- 


\section{Week Treatment}

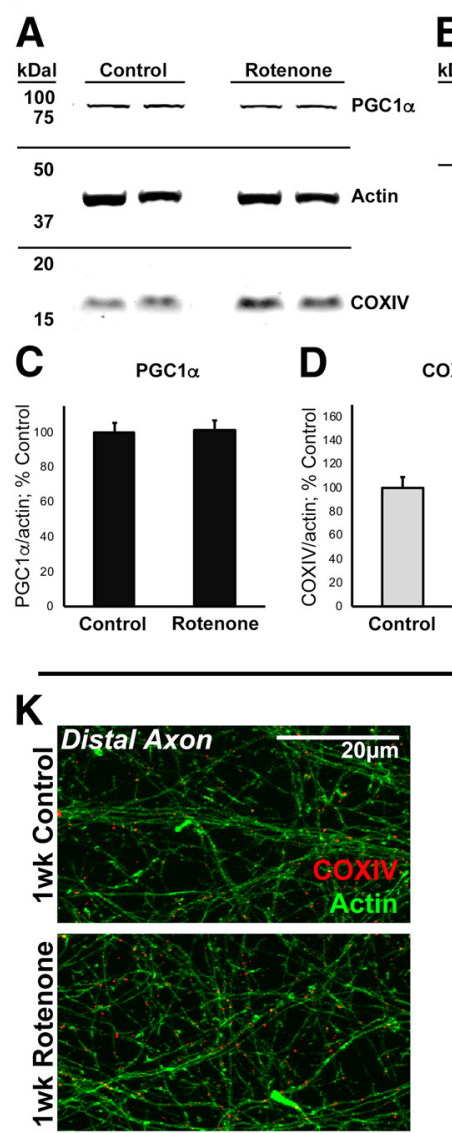

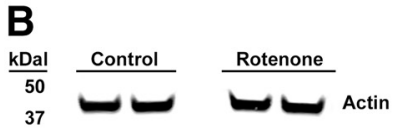

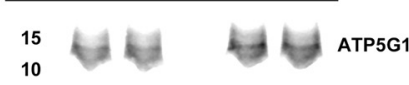

10

coxiv
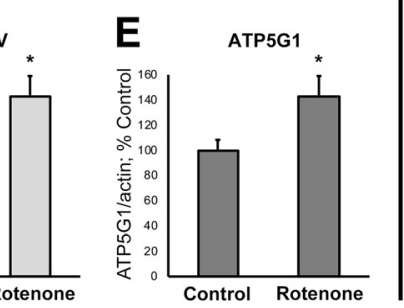

\section{Week Treatment}
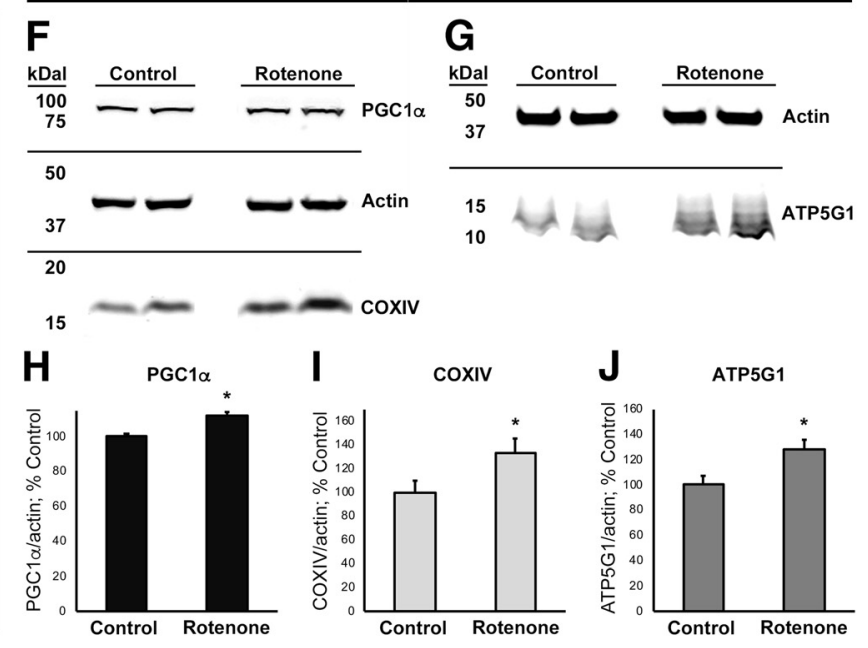

$\mathbf{L}$

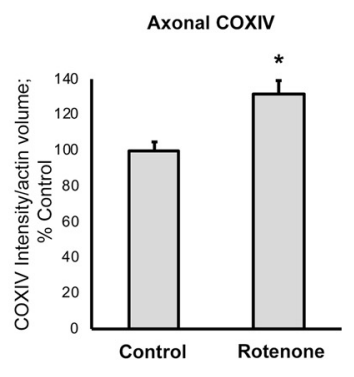

M

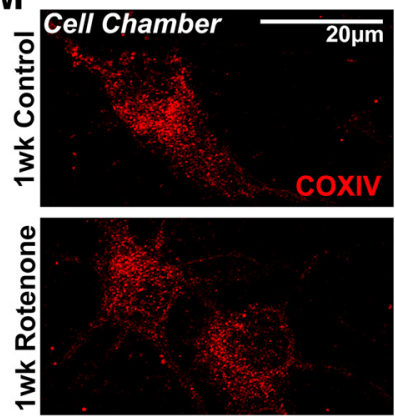

N

Cell Body Coxiv

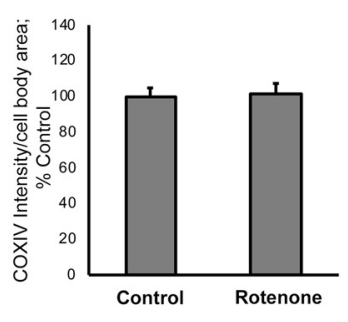

Figure 4. Effect of chronic rotenone on neuronal expression of PGC1 $\alpha$, COXIV, and ATP5G1. Primary neurons were treated with DMSO vehicle control or $1 \mathrm{~nm}$ rotenone for 1 week (A-E) or 2 weeks $(\boldsymbol{F}-\boldsymbol{J})$ and collected for Western blot and immunochemical detection analyses of PGC1 $\alpha$ and $\operatorname{COXIV}(\boldsymbol{A}, \boldsymbol{F})$, and of ATP5G1 $(\boldsymbol{B}, \boldsymbol{G})$. C, We observed that 1 week of chronic rotenone exposure did not alter PGC $1 \alpha$ levels $\left(t_{(21)}=0.17 ; p=0.87\right.$; two-tailed unpaired $t$ test). $\boldsymbol{D}$, Levels of COXIV were significantly increased after 1 week of rotenone exposure compared with vehicle control (difference in means $=+51.4 ; t_{(21)}=2.5 ;{ }^{*} p=0.020$; two-tailed unpaired $t$ test). $\boldsymbol{E}$, Levels of ATP5G1 were also significantly increased after 1 week of rotenone exposure compared with vehicle control difference in means $=+43.2 ; t_{(24)}=2.3 ;{ }^{*} p=0.028$; two-tailed unpaired $t$ test). $\boldsymbol{H}$, After 2 weeks of chronic rotenone exposure, PGC $\alpha$ levels were significantly increased compared with vehicle control (difference in means $=+11.7 ; t_{(22)}=3.7 ;{ }^{*} p=0.0013$; two-tailed unpaired $t$ test). $I$, Levels of COXIV remained significantly elevated after 2 weeks of rotenone exposure compared with vehicle control (difference in means $=+33.2 ; t_{(22)}=2.14 ; p=0.044$; two-tailed unpaired $t$ test). $J$, Levels of ATP5G1 also remained significantly increased after 2 weeks of rotenone exposure compared with vehicle control (difference in means $=+23.3 ; t_{(24)}=2.66 ; p=0.014$; two-tailed unpaired $t$ test; $n=11-13$; percentage of control \pm SEM). To assess neuroanatomical localization of changes in COXIV protein, primary neurons were grown in microfluidic devices (Xona Microfluidics) to environmentally separate cell bodies and dendrites from axons. $\boldsymbol{K}, \boldsymbol{M}$, Neurons were treated with DMSO vehicle control or $1 \mathrm{~nm}$ rotenone for 1 week and then fixed for fluorescent immunochemical detection of COXIV and detection of actin via phalloidin. $L$, Quantitative fluorescence analyses demonstrated that, after 1 week of $1 \mathrm{~nm}$ rotenone, COXIV protein levels in axons significantly increased compared with vehicle control control (difference in means $=+31.8 ; t_{(47)}=3.72 ; p=$ 0.0005 ; two-tailed unpaired $t$ test; $n=26$ control and $n=23$ rotenone image fields representing three independent neuron preps \pm SEM). $N$, COXIV levels in cell bodies, however, were unchanged following 1 week of rotenone compared with control ( $t_{(151)}=0.17 ; p=0.87$; two-tailed unpaired $t$ test; $n=91$ control and $n=62$ rotenone cells representing three independent neuron preps \pm SEM).
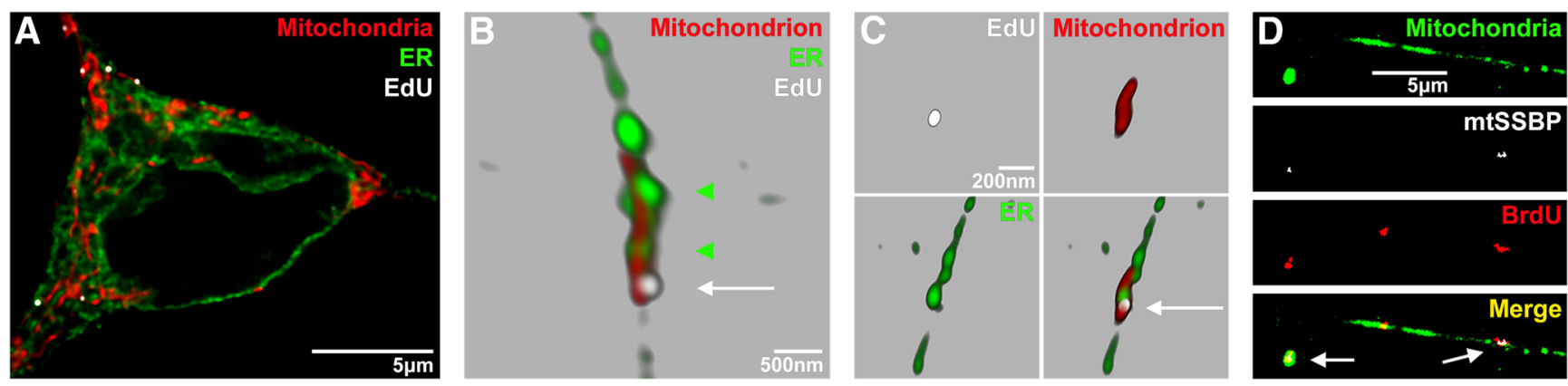

Figure 5. STED superresolution microscopy reveals mitochondrial-ER interaction at axonal mtDNA replication sites, and mtSSBP localization suggests active $m+D N A$ replication in axons. $A-C$, Primary cortical neurons were cotransfected with mtDsRed2 (Mitochondria, Mitochondrion) and GFP-tagged endoplasmic reticulum protein Sec61 $\beta$ (ER). At DIV14, cells were exposed to EdU (10 $\mu \mathrm{M}$ ) for $3 \mathrm{~h}$ and then fixed and stained for EdU using the Click-iT Alexa Fluor 647 kit and for GFP via immunofluorescence. STED superresolution microscopy was used to examine EdU staining relative to both mitochondria and ER in the soma $(\boldsymbol{A})$ and in axons $(\boldsymbol{B}, \boldsymbol{C}$. We observed ER-mitochondrial interaction in axons ( $\boldsymbol{B}$, green arrowheads) and specifically at sites of mtDNA EdU incorporation (C, white arrow). D, Primary neurons were transfected with PA-mtGFP (Mitochondria) and at DIV14 exposed to BrdU (10 $\mu \mathrm{M})$ for $3 \mathrm{~h}$. Cells were immunofluorescently stained for BrdU and mtSSBP. We observed mtSSBP colocalized with BrdU puncta within distal axonal mitochondria, suggesting active mtDNA replication. 


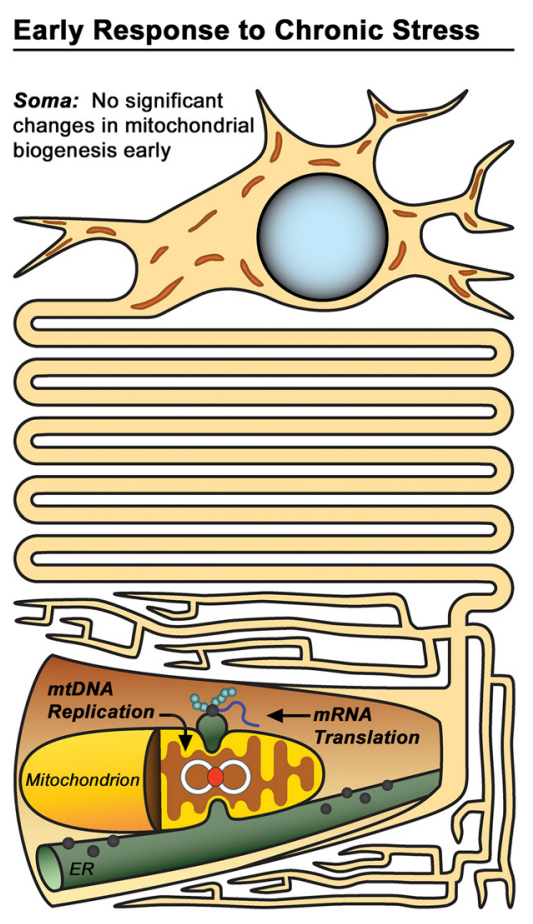

Distal Axon: Localized upregulation of mitochondrial biogenesis in response to stress-induced increases in demand; increased mitochondria in distal axons.

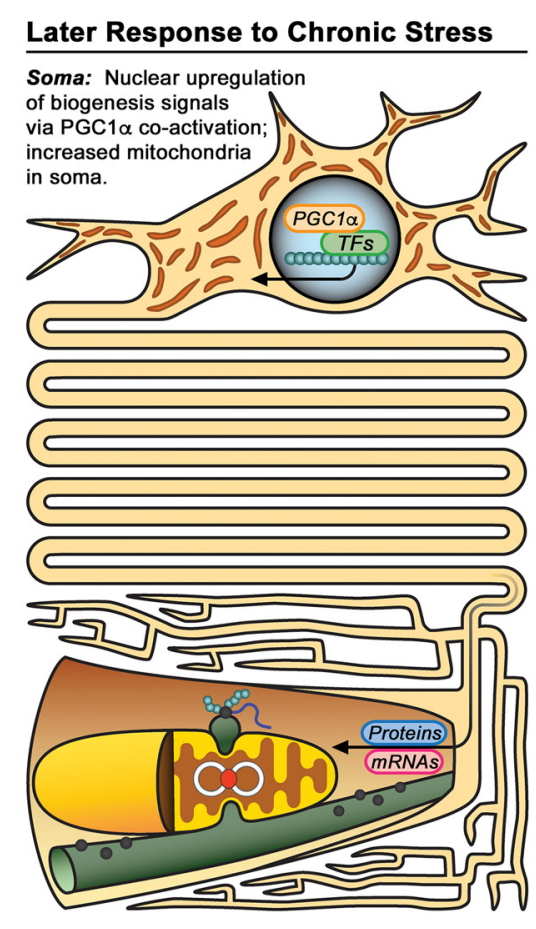

Distal Axon: Increased peripherial mitochondrial biogenesis is maintained, possibly in part by soma upregulation of resources for replication.

\section{Pathogenic Conditions in Vulnerable Neurons}

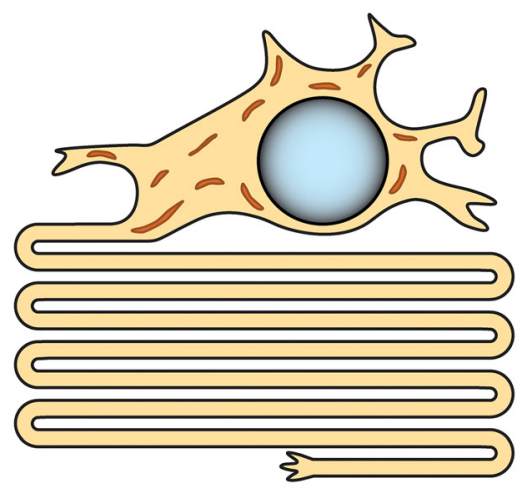

Distal Axon: Lower capacity for localized biogenesis upregulation in distal axons in response to stress may lead to bioenergetic distress and neuritic retraction ahead of cell body death.

Figure 6. Proposed model of compartmentalized mitochondrial biogenesis response to stress in neurons. Early response to chronic stress: As an initial response to low, chronic mitochondrial stress, high-energy demanding arborized distal axons upregulate mitochondrial biogenesis locally, increasing mtDNA replication, mRNA translation, and mitochondrial density to preserve axonal health and function. This happens independently of the soma, where no significant changes in mitochondrial biogenesis have yet occurred. Later response to chronic stress: As prolonged stress continues to tax mitochondrial function, nuclear upregulation of the "master mitochondrial biogenesis regulator" transcription coactivator PGC1 $\alpha$ increases activation of mitochondrial biogenesis transcription factors (TFs), including NRF-1 and NRF-2. Mitochondrial biogenesis increases in the soma, leading to increased somal mitochondrial density and increased resources (such as nuclear-expressed mitochondrially targeted transcription factors, proteins, and mRNAs) are available for transport down the axon to maintain localized mitochondrial biogenesis distally. Pathogenic conditions in vulnerable neurons: Neurons vulnerable to mitochondrial stressors may lack the ability to quickly upregulate local mitochondrial biogenesis in distal axons in response to stress. The poor early response to mitochondrial distress in the distal axon may lead to loss of the axonal projection and subsequent death of the neuron.

dition to cell bodies and that distal axonal mitochondrial biogenesis is upregulated in response to a chronic stressor linked to PD.

\section{Mitochondrial biogenesis in distal axons}

It is generally assumed that mitochondrial biogenesis takes place only in cell bodies within the perinuclear regions, as has been shown for muscle cells and PC12 cells (Davis and Clayton, 1996; Schultz et al., 1998). However, our present studies demonstrated that mtDNA replication occurs in the most distal axons as well, providing new evidence that at least one important component of biogenesis of new mitochondria does occur far from the cell body. In addition, we provided the first demonstration of mtDNA replication sites adjacent to ER in axons, providing evidence supporting localized axonal mitochondrial-ER sites of replication and division into new mitochondria, as was previously observed in cell bodies of yeast and replicating mammalian cells (Murley et al., 2013; Lewis et al., 2016). Although it is difficult to definitively delineate neuroanatomical localization of mitochondrial biogenesis because most other measures of biogenesis cannot give anatomical localization, our present findings are bolstered by our previously reported findings of increased mitochondrial density in neurons under similar conditions (Arnold et al., 2011). In that study, under similar chronic exposures, we found localized increases in mitochondrial density in distal axons without evidence of increased anterograde transport, decreased retrograde transport, decreased distal mitophagy, or concurrent mitochondrial density increases in the soma, further supporting the presence of axonal biogenesis.

Coordination of the components of mitochondrial biogenesis in neurons is not well understood. The supposition that mitochondrial biogenesis takes place only in neuronal cell bodies near nuclei, with new mitochondria transported to distal regions via axonal transport, arises from the fact that translation of nuclearencoded, mitochondrially targeted proteins has to be coordinated with membrane biosynthesis, mtDNA replication, and mitochondrial division (Davis and Clayton, 1996; Nisoli et al., 2004). In addition, upregulation of nuclear gene expression for mitochondrially targeted proteins and mitochondrial transcription factors via the nuclear transcription coactivator PGC1 $\alpha$ is one known regulator of the coordinated mitochondrial biogenesis process (Stevens et al., 2015; Lee et al., 2017). However, a system that would not allow for biogenesis locally would be an inefficient means of replacing dysfunctional mitochondria at distal terminals of long axons and thus would seem detrimental to survival in neurons with long or high-energy-demand projections. This is particularly relevant to neuronal populations vulnerable in PD neurodegeneration, which contain particularly long axons with extensive arborization (Braak et al., 2004; Surmeier et al., 2017).

The present study is the first to examine mitochondrial biogenesis directly in CNS distal axons. There has been previous support for non-cell-body mtDNA replication in the PNS. Two 
studies using thymidine analogs in PNS neurons detected mtDNA replication in both soma and proximal neurites (Amiri and Hollenbeck, 2008; Lentz et al., 2010), with one study showing that $\mathrm{mtDNA}$ replication occurred in the axons of peripheral sympathetic ganglia neurons after being physically separated from cell bodies (Amiri and Hollenbeck, 2008). A third study was performed in CNS neurons, examining BrdU incorporation into both somal and neuritic mitochondria in mouse hippocampal neurons after acute exposure to toxicants and in neurons from a transgenic mouse Alzheimer's disease model (Calkins and Reddy, 2011). However, neuritic origin of the mtDNA replication could not be distinguished from transported somal mitochondria in that study because prolonged BrdU exposure periods ( $20 \mathrm{~h}$ ) were used and distal axons were not delineated. Our present studies, then, provide the first definitive confirmation of CNS distal axonal mtDNA replication and further link it to both increased mitochondrial density and mitochondrial-ER localization.

\section{Exposure to a chronic PD-relevant stressor may cause early increased axonal mitochondrial biogenesis}

Chronic exposure to low, nonlethal concentrations of the mitochondrial toxin rotenone results in a specific PD phenotype in rats, with neurodegeneration and pathological changes typical of human disease (Betarbet et al., 2000; Cannon et al., 2009), and chronic rotenone is an established PD model. Rotenone exposure is a risk factor in human PD (Tanner et al., 2011; Wirdefeldt et al., 2011) and elucidation of the mechanisms involved in chronic rotenone exposure is likely to yield information relevant to $\mathrm{PD}$ neuropathogenesis. Both human PD and chronic rotenone exposure lead to loss of dopaminergic axon loss first, which is followed by cell death (Betarbet et al., 2000; Tagliaferro and Burke, 2016). Therefore, early adverse effects on distal axonal mitochondrial homeostasis may have key involvement in initial changes leading to later neuron death.

We previously demonstrated that low-dose rotenone exposure results in early changes in axonal mitochondrial fission, fusion, and transport before cell death (Arnold et al., 2011). We also observed a temporal effect of increasing mitochondrial density, where mitochondrial density in distal axons increased early and without concurrent increases in somal density, but density was increased in both axons and cell bodies at later time points (Arnold et al., 2011). Our present studies demonstrate similar time-dependent alterations in distal axonal mtDNA replication after chronic exposure to concentrations of rotenone that cause early neurite pathology but no cell death. Initially, chronic sublethal rotenone exposure caused increased mtDNA replication localized to neurites and only after longer exposures was there a concomitant increase in cell body mtDNA replication. Our work further confirms that chronic rotenone exposure increases mtDNA replication specifically in distal axons, along with concomitant upregulation of mitochondrially targeted protein known to be locally translated in axons via axonally transported mRNA. These changes correlate to the anatomic localization and time course of increases in mitochondrial density in neurons after rotenone exposure observed in our previous work (Arnold et al., 2011).

We hypothesize that the rotenone-induced early upregulation mitochondrial biogenesis in axons and increased mitochondrial density is a compensatory process in response to chronic lowlevel mitochondrial disruption in an attempt to prevent cell death. In neurons with a lower capacity for axonal mitochondrial biogenesis, risk for subsequent neuron death would be increased. If the localized mitochondrial biogenesis response is insufficient, mitochondrial stress in energy-requiring distal axons could trigger axonal neurodegeneration and subsequent neuronal cell death. This is particularly relevant for PD neurodegeneration because it is known that genes such as Parkin, loss-of-function mutations of which cause PD, are known to regulate mitochondrial biogenesis (Stevens et al., 2015; Lee et al., 2017).

\section{Proposed model of early and late regulation of neuronal mitochondrial biogenesis in response to $\mathrm{PD}$-relevant chronic stress}

Our present studies support the following proposed model. After initiation of a chronic neurotoxic exposure such as rotenone, which is known to result in axonal loss before cell death, the initial response to mitochondrial stress may be upregulation of biogenesis through localized means (Fig. 6). Detailed imaging studies have demonstrated that ribosomes on ER, which are capable of protein translation, are present throughout the length of axons (Luarte et al., 2018). mRNAs of nuclear-expressed mitochondrially targeted proteins have been shown to be transported down axons and regulation of axon protein expression affects mitochondrial function (Gioio et al., 2001; Hillefors et al., 2007; Willis et al., 2011; Spillane et al., 2013; Minis et al., 2014; Aschrafi et al., 2016). More directly, dynamic regulation of localized translation of nuclear-expressed mitochondrially targeted proteins in axons has been demonstrated recently (Shigeoka et al., 2018). We believe it is possible that, in distal axons, a localized pool of mRNA and translation machinery combined with signaling mechanisms for mtDNA replication and other steps of biogenesis are available for more rapid upregulation of mitochondrially targeted protein synthesis, particularly in response to stress. As stress continues over a longer period, PGC1 $\alpha$ is upregulated, leading to transcriptional coactivation of downstream effectors that could then upregulate overall mitochondrial biogenesis throughout the neuron. An inadequate early compensatory response to stress in the axons of vulnerable neurons, then, could lead to initiation of neurodegeneration. Further studies are necessary to verify this hypothesized model.

\section{References}

Amiri M, Hollenbeck PJ (2008) Mitochondrial biogenesis in the axons of vertebrate peripheral neurons. Dev Neurobiol 68:1348-1361. CrossRef Medline

Arnold B, Cassady SJ, VanLaar VS, Berman SB (2011) Integrating multiple aspects of mitochondrial dynamics in neurons: age-related differences and dynamic changes in a chronic rotenone model. Neurobiol Dis 41: 189-200. CrossRef Medline

Aschrafi A, Kar AN, Gale JR, Elkahloun AG, Vargas JN, Sales N, Wilson G, Tompkins M, Gioio AE, Kaplan BB (2016) A heterogeneous population of nuclear-encoded mitochondrial mRNAs is present in the axons of primary sympathetic neurons. Mitochondrion 30:18-23. CrossRef Medline

Berman SB, Chen YB, Qi B, McCaffery JM, Rucker EB 3rd, Goebbels S, Nave KA, Arnold BA, Jonas EA, Pineda FJ, Hardwick JM (2009) Bcl-x L increases mitochondrial fission, fusion, and biomass in neurons. J Cell Biol 184:707-719. CrossRef Medline

Betarbet R, Sherer TB, MacKenzie G, Garcia-Osuna M, Panov AV, Greenamyre JT (2000) Chronic systemic pesticide exposure reproduces features of Parkinson's disease. Nat Neurosci 3:1301-1306. CrossRef Medline

Bose A, Beal MF (2016) Mitochondrial dysfunction in Parkinson's disease. J Neurochem 139:216-231. CrossRef Medline

Braak H, Ghebremedhin E, Rüb U, Bratzke H, Del Tredici K (2004) Stages in the development of Parkinson's disease-related pathology. Cell Tissue Res 318:121-134. CrossRef Medline

Bradford MM (1976) A rapid and sensitive method for the quantitation of microgram quantities of protein utilizing the principle of protein-dye binding. Anal Biochem 72:248-254. CrossRef Medline 
Calkins MJ, Reddy PH (2011) Assessment of newly synthesized mitochondrial DNA using BrdU labeling in primary neurons from Alzheimer's disease mice: Implications for impaired mitochondrial biogenesis and synaptic damage. Biochim Biophys Acta 1812:1182-1189. CrossRef Medline

Cannon JR, Tapias V, Na HM, Honick AS, Drolet RE, Greenamyre JT (2009) A highly reproducible rotenone model of Parkinson's disease. Neurobiol Dis 34:279-290. CrossRef Medline

Curth U, Urbanke C, Greipel J, Gerberding H, Tiranti V, Zeviani M (1994) Single-stranded-DNA-binding proteins from human mitochondria and escherichia coli have analogous physicochemical properties. Eur J Biochem 221:435-443. CrossRef Medline

Davis AF, Clayton DA (1996) In situ localization of mitochondrial DNA replication in intact mammalian cells. J Cell Biol 135:883-893. CrossRef Medline

Detmer SA, Chan DC (2007) Functions and dysfunctions of mitochondrial dynamics. Nat Rev Mol Cell Biol 8:870-879. CrossRef Medline

Gioio AE, Eyman M, Zhang H, Lavina ZS, Giuditta A, Kaplan BB (2001) Local synthesis of nuclear-encoded mitochondrial proteins in the presynaptic nerve terminal. J Neurosci Res 64:447-453. CrossRef Medline

Haines KM, Feldman EL, Lentz SI (2010) Visualization of mitochondrial DNA replication in individual cells by EdU signal amplification. J Vis Exp 45: pii: 2147. CrossRef Medline

Hammond JB, Kruger NJ (1988) The Bradford method for protein quantitation. Methods Mol Biol 3:25-32. CrossRef Medline

Hillefors M, Gioio AE, Mameza MG, Kaplan BB (2007) Axon viability and mitochondrial function are dependent on local protein synthesis in sympathetic neurons. Cell Mol Neurobiol 27:701-716. CrossRef Medline

Kar AN, Sun CY, Reichard K, Gervasi NM, Pickel J, Nakazawa K, Gioio AE, Kaplan BB (2014) Dysregulation of the axonal trafficking of nuclearencoded mitochondrial mRNA alters neuronal mitochondrial activity and mouse behavior. Dev Neurobiol 74:333-350. CrossRef Medline

Karbowski M, Arnoult D, Chen H, Chan DC, Smith CL, Youle RJ (2004) Quantitation of mitochondrial dynamics by photolabeling of individual organelles shows that mitochondrial fusion is blocked during the bax activation phase of apoptosis. J Cell Biol 164:493-499. CrossRef Medline

Lee Y, et al. (2017) PINK1 primes parkin-mediated ubiquitination of PARIS in dopaminergic neuronal survival. Cell Rep 18:918-932. CrossRef Medline

Lentz SI, Edwards JL, Backus C, McLean LL, Haines KM, Feldman EL (2010) Mitochondrial DNA (mtDNA) biogenesis: visualization and duel incorporation of BrdU and EdU into newly synthesized mtDNA in vitro. J Histochem Cytochem 58:207-218. CrossRef Medline

Lewis SC, Uchiyama LF, Nunnari J (2016) ER-mitochondria contacts couple mtDNA synthesis with mitochondrial division in human cells. Science 353:aaf5549. CrossRef Medline

Li PA, Hou X, Hao S (2017) Mitochondrial biogenesis in neurodegeneration. J Neurosci Res 95:2025-2029. CrossRef Medline

Luarte A, Cornejo VH, Bertin F, Gallardo J, Couve A (2018) The axonal endoplasmic reticulum: one organelle-many functions in development, maintenance, and plasticity. Dev Neurobiol 78:181-208. CrossRef Medline

McCoy MK, Cookson MR (2012) Mitochondrial quality control and dynamics in Parkinson's disease. Antioxid Redox Signal 16:869-882. CrossRef Medline

Minis A, Dahary D, Manor O, Leshkowitz D, Pilpel Y, Yaron A (2014) Subcellular transcriptomics-dissection of the mRNA composition in the axonal compartment of sensory neurons. Dev Neurobiol 74:365-381. CrossRef Medline

Murley A, Lackner LL, Osman C, West M, Voeltz GK, Walter P, Nunnari J (2013) ER-associated mitochondrial division links the distribution of mitochondria and mitochondrial DNA in yeast. Elife 2:e00422. CrossRef Medline

Natera-Naranjo O, Kar AN, Aschrafi A, Gervasi NM, Macgibeny MA, Gioio AE, Kaplan BB (2012) Local translation of ATP synthase subunit 9 mRNA alters ATP levels and the production of ROS in the axon. Mol Cell Neurosci 49:263-270. CrossRef Medline

Nisoli E, Clementi E, Moncada S, Carruba MO (2004) Mitochondrial biogenesis as a cellular signaling framework. Biochem Pharmacol 67:1-15. CrossRef Medline

O’Donnell KC, Lulla A, Stahl MC, Wheat ND, Bronstein JM, Sagasti A
(2014) Axon degeneration and PGC-1alpha-mediated protection in a zebrafish model of alpha-synuclein toxicity. Dis Model Mech 7:571-582. CrossRef Medline

Sanders LH, McCoy J, Hu X, Mastroberardino PG, Dickinson BC, Chang CJ, Chu CT, Van Houten B, Greenamyre JT (2014) Mitochondrial DNA damage: molecular marker of vulnerable nigral neurons in Parkinson's disease. Neurobiol Dis 70:214-223. CrossRef Medline

Schindelin J, Arganda-Carreras I, Frise E, Kaynig V, Longair M, Pietzsch T, Preibisch S, Rueden C, Saalfeld S, Schmid B, Tinevez JY, White DJ, Hartenstein V, Eliceiri K, Tomancak P, Cardona A (2012) Fiji: an opensource platform for biological-image analysis. Nat Methods 9:676-682. CrossRef Medline

Schneider CA, Rasband WS, Eliceiri KW (2012) NIH image to ImageJ: 25 years of image analysis. Nat Methods 9:671-675. CrossRef Medline

Schultz RA, Swoap SJ, McDaniel LD, Zhang B, Koon EC, Garry DJ, Li K, Williams RS (1998) Differential expression of mitochondrial DNA replication factors in mammalian tissues. J Biol Chem 273:3447-3451. CrossRef Medline

Shigeoka T, Jung J, Holt CE, Jung H (2018) Axon-TRAP-RiboTag: affinity purification of translated mRNAs from neuronal axons in mouse in vivo. Methods Mol Biol 1649:85-94. CrossRef Medline

Sivakumar S, Porter-Goff M, Patel PK, Benoit K, Rhind N (2004) In vivo labeling of fission yeast DNA with thymidine and thymidine analogs. Methods 33:213-219. CrossRef Medline

Spillane M, Ketschek A, Merianda TT, Twiss JL, Gallo G (2013) Mitochondria coordinate sites of axon branching through localized intra-axonal protein synthesis. Cell Rep 5:1564-1575. CrossRef Medline

Starnes MC, Cheng YC (1987) Cellular metabolism of 2',3'-dideoxycytidine, a compound active against human immunodeficiency virus in vitro. J Biol Chem 262:988-991. Medline

Stevens DA, Lee Y, Kang HC, Lee BD, Lee YI, Bower A, Jiang H, Kang SU, Andrabi SA, Dawson VL, Shin JH, Dawson TM (2015) Parkin loss leads to PARIS-dependent declines in mitochondrial mass and respiration. Proc Natl Acad Sci U S A 112:11696-11701. CrossRef Medline

Surmeier DJ, Obeso JA, Halliday GM (2017) Selective neuronal vulnerability in parkinson disease. Nat Rev Neurosci 18:101-113. CrossRef Medline

Tagliaferro P, Burke RE (2016) Retrograde axonal degeneration in parkinson disease. J Parkinsons Dis 6:1-15. CrossRef Medline

Tanner CM, Kamel F, Ross GW, Hoppin JA, Goldman SM, Korell M, Marras C, Bhudhikanok GS, Kasten M, Chade AR, Comyns K, Richards MB, Meng C, Priestley B, Fernandez HH, Cambi F, Umbach DM, Blair A, Sandler DP, Langston JW (2011) Rotenone, paraquat, and Parkinson's disease. Environ Health Perspect 119:866-872. CrossRef Medline

Taylor AM, Blurton-Jones M, Rhee SW, Cribbs DH, Cotman CW, Jeon NL (2005) A microfluidic culture platform for CNS axonal injury, regeneration and transport. Nat Methods 2:599-605. CrossRef Medline

Tiranti V, Rossi E, Ruiz-Carrillo A, Rossi G, Rocchi M, DiDonato S, Zuffardi O, Zeviani M (1995) Chromosomal localization of mitochondrial transcription factor A (TCF6), single-stranded DNA-binding protein (SSBP), and endonuclease G (ENDOG), three human housekeeping genes involved in mitochondrial biogenesis. Genomics 25:559-564. CrossRef Medline

Van Laar VS, Berman SB (2009) Mitochondrial dynamics in Parkinson's disease. Exp Neurol 218:247-256. CrossRef Medline

Van Laar VS, Berman SB (2013) The interplay of neuronal mitochondrial dynamics and bioenergetics: implications for Parkinson's disease. Neurobiol Dis 51:43-55. CrossRef Medline

Voeltz GK, Prinz WA, Shibata Y, Rist JM, Rapoport TA (2006) A class of membrane proteins shaping the tubular endoplasmic reticulum. Cell 124: 573-586. CrossRef Medline

Willis DE, Xu M, Donnelly CJ, Tep C, Kendall M, Erenstheyn M, English AW, Schanen NC, Kirn-Safran CB, Yoon SO, Bassell GJ, Twiss JL (2011) Axonal localization of transgene mRNA in mature PNS and CNS neurons. J Neurosci 31:14481-14487. CrossRef Medline

Wirdefeldt K, Adami HO, Cole P, Trichopoulos D, Mandel J (2011) Epidemiology and etiology of Parkinson's disease: a review of the evidence. Eur J Epidemiol 26:S1-S58. CrossRef Medline

Zimmermann W, Chen SM, Bolden A, Weissbach A (1980) Mitochondrial DNA replication does not involve DNA polymerase alpha. J Biol Chem 255:11847-11852. Medline 